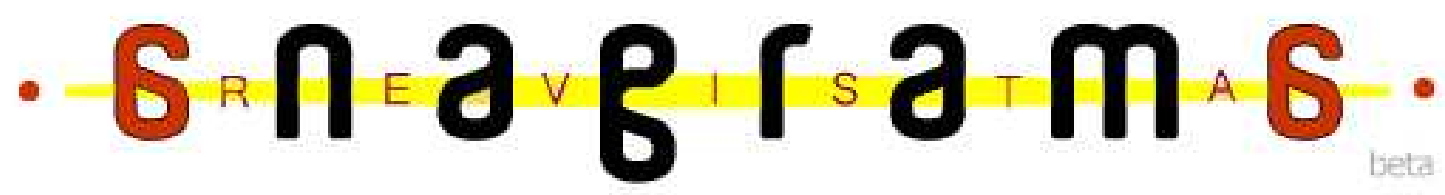

\section{Jogos eletrônicos, protagonistas femininas e redução de estereótipos: a série Tomb Raider}

Carolina de Almeida Gomes da Cruz'

Francisco José Paoliello Pimenta?

\section{Resumo}

O presente trabalho aborda a problemática da representação de personagens femininas nos jogos eletrônicos, partindo da hipótese de que o público feminino em crescimento influencia em uma representação menos estereotipada de protagonistas femininas. Considerando esse processo no sentido estético, relação com a temática e efeito nas jogadoras, foram analisadas as mudanças na representação da protagonista Lara Croft em três jogos ao longo da série Tomb Raider. Foi constatada uma redução da forma estereotipada em geral, no sentido estético e na presença mais complexa na narrativa.

Palauras-chaue: jogos eletrônicos; Tomb Raider; jogadoras; estereótipo.

Os jogos e o aumento do público feminino

A indústria dos jogos é hoje extremamente lucrativa, e um dos meios de entretenimento em maior destaque. Prevista para exceder os 76 bilhões mundialmente em 2013, tem também muito destaque no Brasil, um mercado em crescimento que já se enquadra como o quarto maior do mundo

\footnotetext{
${ }^{1}$ Estudante de Graduação do $5^{\circ}$ semestre do Curso de Jornalismo da FACOM/UFJF. Bolsista do $1^{\circ}$ período no programa Jovens Talentos para a Ciência/Capes e atual bolsista do PET/Facom da Universidade Federal de Juiz de Fora.

${ }^{2}$ Orientador do trabalho. Professor do Departamento de Comunicação e Artes da Faculdade de Comunicação Social da Universidade Federal de Juiz de Fora.
} 
Acompanhando o crescimento e importância da indústria em si, é possível perceber várias mudanças não só no conteúdo, mas também no público que consome e aprecia os seus produtos. $\mathrm{O}$ aumento do público feminino é um dos fenômenos mais relevantes na indústria atualmente, em termos de mercado. De acordo com uma pesquisa de 2012 feita pela ESA (Entertainment Software Association), nos EUA as mulheres já representam 47\% dos jogadores de títulos para computador e console; as mulheres com ou acima de 18 anos representam uma parcela maior da população de jogadores (30\%) do que garotos de 17 anos ou mais novos (18\%), anteriormente os maiores consumidores de jogos.

O aumento da presença feminina como público é evidente também em relação ao crescimento da indústria como um todo, em especial o setor específico de jogos online e dispositivos móveis, incluindo também jogos casuais ${ }^{3}$. No Brasil, reunindo todos os tipos de jogos, o público feminino já corresponde a $47 \%$ dos jogadores.

\section{Tendências no meio}

O modelo clássico de jogos, que se enquadra nos produtos para computador e console (foco desta pesquisa), possui um caráter importante na análise dos conteúdos e representação de gêneros na indústria. Nessas plataformas, estão os chamados jogos "hardcore", que são mais avançados e geralmente produzidos por grandes empresas. O crescimento do público feminino nos videojogos enquadrados nesse perfil se destaca não só pelo mercado tradicionalmente masculino de tais jogos, mas também por exigirem maior dedicação e tempo do usuário, com um sistema (e, normalmente, gráficos e história) mais complexo.

Esses títulos não só representam a indústria e a seriedade dos seus produtos, como estão incluídos em uma tendência já apontada por Janet Murray, de intensificação do caráter dos jogos como uma nova forma de narrativa. Essa característica é ainda mais forte naqueles que valorizam a história e o desenvolvimento dos personagens:

Esses novos formatos para contar histórias variam dos videogames do tipo "fogo neles!" (shoot-'em-up) e das masmorras virtuais dos role-playing games (RPG)

\footnotetext{
${ }^{3}$ Jogos casuais possuem jogabilidade mais simples do que os títulos tradicionais, exigindo pouco tempo e compromisso dos jogadores, mas com um amplo mercado, diversificado em várias plataformas (computador, dispositivos móveis, online, etc.).
} 
da internet até os hipertextos literários pós-modernos. Essa abrangente gama de arte narrativa traz consigo a promessa de um novo meio de expressão tão diversificado como os livros impressos e o cinema. (MURRAY, 2003, p. 41)

Ainda de acordo com Murray, em parte, "questões sobre o conteúdo e forma dos videogames, são, de fato, indagações sobre o próprio poder da narrativa" (MURRAY, 2003, prefácio). A produção de histórias complexas também permite uma representação diferenciada e mais profunda, se comparada com o início da mídia. A partir da análise de tais títulos, é possível determinar um perfil mais claro das personagens, abordando tanto o aspecto físico quanto a maneira como o personagem é inserido na trama.

\section{O estereótipo de personagens femininas}

Com o desenvolvimento das possibilidades gráficas, a figura feminina ganhou destaque por meio de representações mais realistas, mas que incluíram também a ampliação de sua exploração comercial. As poucas personagens femininas possuíam uma participação em grande parte limitada ao papel de "princesa indefesa" ou à "femme-fatale", por exemplo, tendo em geral pouca relevância para a história, por meio dos chamados sexroles. Em termos de representação física, foi confirmado, a partir de análises de capas de jogos, trailers e outros materiais relacionados, que o corpo das personagens femininas é na grande maioria sexualizado, acompanhado de roupas mais reveladoras, distantes do contexto do jogo (MILLER; SUMMERS, 2007), (MOU; PENG, 2009) (MARTINS et al, 2009).

Além da imagem estereotipada, a presença de personagens femininas geralmente foi reduzida e nem sempre associada a um título de ampla vendagem. Apesar desse padrão do mercado, algumas mudanças já foram constatadas na presença e imagem feminina nos videojogos nos últimos anos. Em 2007, foi estudado o aumento de protagonistas femininas, assim como a maior frequência de personagens fortes e competentes em posição dominante, o chamado "fenômeno Lara Croft" (JANSZ; MARTIS, 2007).

Já o game designer Lee Sheldon, destaca a possibilidade de desenvolver esse tipo de personagem a partir do equilíbrio entre as várias dimensões que o compõe:

Precisamos nos perguntar como fazê-las personagens atraentes mesmo se não forem concebidas de forma tão estereotípica. A dimensão física é a parte fácil. Isso também significa que é fácil depender muito dela. Uma vez que fazemos o 
esforço de revelar suas dimensões psicológicas e sociológicas, a dimensão física ganha de novo sua importância adequada, igual às outras. (SHELDON, 2004, p. $101)^{4}$

\section{A franquia Tomb Raider}

Nesse sentido, a franquia Tomb Raider não só foi amplamente discutida em termos da presença de protagonistas femininas e no papel da mulher nos jogos, como também constituiu um marco em sua época, com uma protagonista em um título inovador e de vendagem expressiva. O primeiro lançamento acontece em 1996 (produzido pela Core Design) e trata das aventuras de Lara Croft, personagem britânica criada por Toby Gard no jogo de ação-aventura, em que tumbas e relíquias estão ligadas a características sobrenaturais de antigas culturas.

Lara Croft se tornou então a heroína mais bem-sucedida dos games, de acordo com o Guinness World Records Gamer's Edition de 2010, e também a personagem feminina mais reconhecida dos videogames, dentre outros prêmios Contribuiu para esse sucesso os dois filmes com Angelina Jolie nesse papel, distribuídos em 2001 e 2003, refletindo a aparência da personagem nos primeiros títulos. O jogo mais recente, de 2013, já possui previsão de um filme relacionado

Com o aumento da popularidade da franquia e, principalmente, da personagem, a discussão sobre a figura feminina, nesse caso, varia entre a exposição sexualizada e a presença independente e poderosa de Lara Croft. Muito mais do que a aparência física, já direcionada aos interesses do público masculino, o marketing e alguns momentos do próprio jogo acentuavam esse papel desempenhado por Lara Croft.

No final de Tomb Raider II (1997) essa questão já era evidente, com a protagonista começando a tirar a roupa para entrar no banho e dizendo ao jogador: "Você não acha que já viu o bastante?”, para, em seguida, atirar em sua direção. Capas de revistas específicas da mídia, assim como calendários, colocavam Lara como a pin-up dos games, em grande parte em poses sugestivas e seminua.

\footnotetext{
${ }^{4}$ We need to ask ourselves how to make them attractive characters even if they are not so stereotypically conceived. The physical dimension is the easy one. That also means it's easy to rely on it too heavily. Once we make the effort to reveal their psychological and sociological dimensions, the physical dimension regains its proper stature equal to the others. Tradução dos autores
} 
Há que se considerar que essa não é, contudo, a essência do impacto de Lara Croft nessa nova mídia. A arqueóloga de origem nobre apresentava uma posição dominante, com inteligência e um humor característico, em uma época em que protagonistas femininas nos jogos eram muito raras.

Após 17 anos, a franquia Tomb Raider continua presente, sofrendo modificações na abordagem do jogo e imagem de Lara Croft. A pesquisa pretende analisar esse desenvolvimento da personagem e do jogo Tomb Raider, de acordo com a sua existência ao longo das várias fases dos videogames, para compreender se houve ou não uma tendência a representar Lara Croft como menos estereotipada, de acordo com os aspectos a seguir. Foram escolhidos três jogos que representam os momentos marcantes da franquia: Tomb Raider III (1998), Tomb Raider Legend (2006) e Tomb Raider (2013).

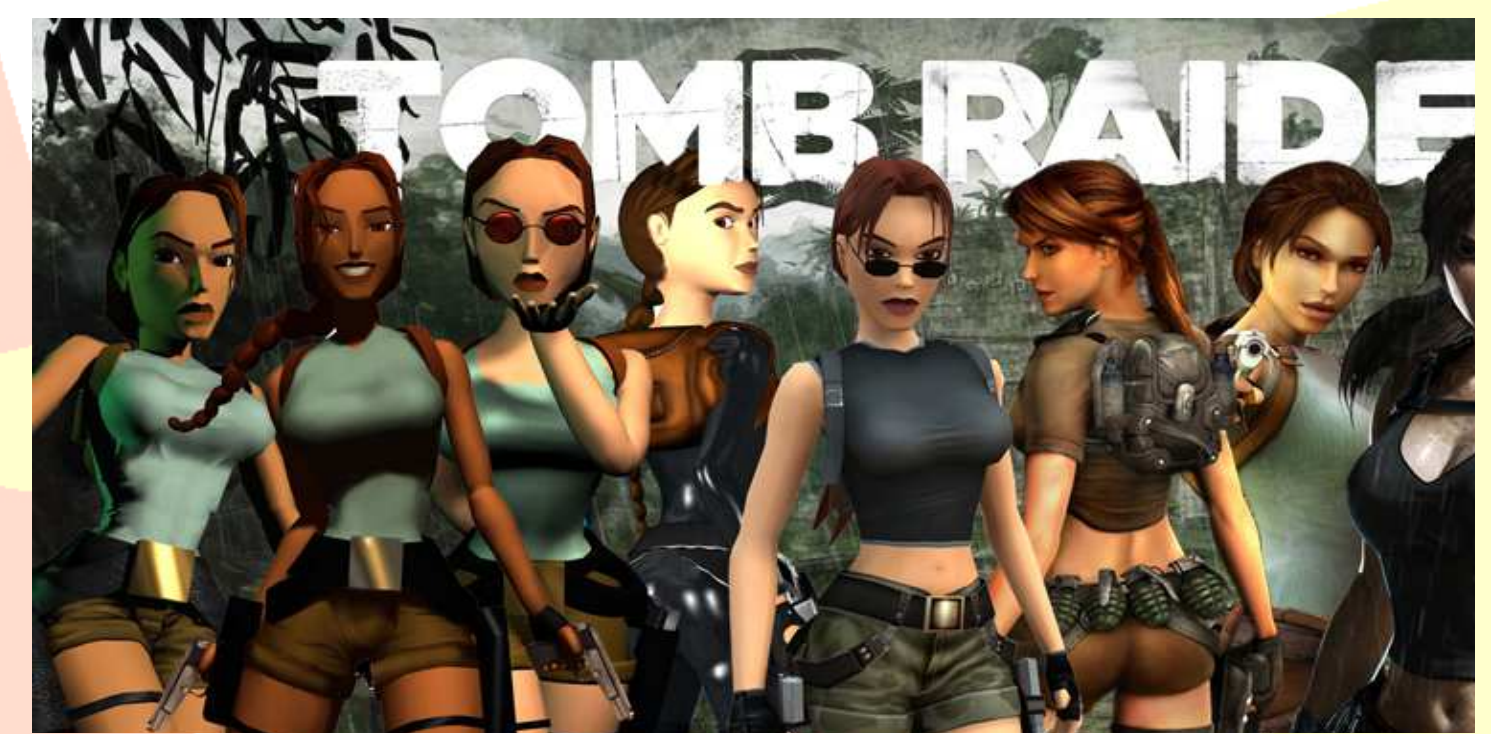

Figura 1: tranformação da aparência da protagonista Lara Croft no jogo Tomb Raider, de 1996 até 2013. Fonte: 〈http://www.undermgzn.com/>

\section{Problema e hipóteses}

A pesquisa trata do problema da representação estereotipada de personagens femininas nos jogos, especificamente de protagonistas. Dentro desse conceito, a hipótese geral é de que o público feminino, que está ingressando em jogos mais avançados, influencia em mudanças na composição de protagonistas femininas desses jogos, de maneira a torná-las menos estereotipadas.

Foram desenvolvidas algumas hipóteses referentes a três diferentes aspectos que compõe a presença da figura feminina: estético, relação com a temática e efeito nas 
jogadoras. Caso a hipótese geral seja verdadeira e haja diminuição do caráter estereotipado da protagonista:

1- Aspectos estéticos: As roupas da protagonista serão mais funcionais, com forma e cores coerentes com o cenário e papel da personagem no jogo, sem que a represente de forma apelativa, destoando do cenário e outros personagens. Não deve haver exposição de partes do corpo que seriam impensáveis em um contexto de batalha, por exemplo.

Feições e corpo mais realistas, no sentido de não serem desenvolvidos para reforçar uma imagem apelativa, fora do contexto. (o realismo aqui não se refere à capacidade gráfica, mas a proporções de corpo da figura em questão).

Os instrumentos (armas ou acessórios) utilizados têm uma função lógica no contexto do jogo, condizentes com o cenário e características da protagonista. São tão ou mais eficientes do que as de outros personagens, especialmente os masculinos, sem ser um símbolo apelativo ou de fraqueza.

2- Relação com a temática: A personagem feminina é retratada de uma maneira mais independente de outras figuras, especialmente em relação a personagens masculinos. A protagonista é inserida na trama mais de acordo com as suas capacidades e sentimentos do que com a sua aparência.

3- Efeito nas jogadoras: As jogadoras veem a trajetória da protagonista ao longo da série como positiva, correspondendo as suas expectativas em termos de jogabilidade e desenvolvimento da personagem, também no sentido de redução do estereótipo físico.

\section{Tomb Raider III: The Aduentures of Lara Croft (1998)}

Aspectos estéticos: A roupa inicial consiste em uma pequena blusa preta, que deixa a barriga de fora, botas e uma calça de camuflagem militar marrom que também aparece em padrão azul. Em parte do jogo (floresta na Índia) e em algumas cutscenes, a protagonista veste a roupa clássica: uma blusa azul com um pequeno short bege, acompanhado de botas, luvas, uma mochila e suporte pra armas. Enquanto no Pacífico Sul Lara veste um short verde e uma camisa branca até logo abaixo do busto, quando em Londres, a vestimenta é justa e de couro preto, com manga comprida e botas. Várias roupas apresentam exposições de partes de forma apelativa e fora do contexto. Mas na última fase, na Antártica, a calça branca e casaco laranja são coerentes quando considerado o clima e os 
inimigos do local (apesar da cor chamativa do casaco em meio à neve). As armas utilizadas, como as pistolas e a shotgun, permitem que a personagem derrote os inimigos de maneira coerente com o cenário e premissa do jogo.

Por conta das limitações gráficas da época em que foi lançado, a aparência da protagonista durante o jogo e em algumas cutscenes $^{5}$, é bastante diferente. A Lara Croft que é visualizada e controlada pelo jogador possui uma silhueta mais simples e fina. $\mathrm{O}$ rosto reflete a ideia base da personagem, como é vista na capa do jogo: lábios grossos, cabelo preso em uma trança, e cintura fina, com o busto de tamanho exagerado; essas características são bem mais fortes nas cutscenes.

Relação com a temática: As motivações da protagonista ao longo da narrativa são ligadas ao ganho pessoal, mas também afetadas pela forma com que as atitudes dos inimigos têm prejudicado os locais, na trajetória ao longo de vários países. Embora exista essa preocupação, a presença de Lara é geralmente fria e irônica. Sua capacidade é vista pelos inimigos e é também demonstrada pela confiança e experiência. O centro da história não está na sua aparência, nem mesmo nos seus sentimentos, mas principalmente na sua capacidade e na busca pelos artefatos. Não existe uma ligação direta com companheiros, fazendo o percurso de Lara mais solitário e centrado em seus próprios interesses, sem que haja dependência. A protagonista aceita trabalhar para o pesquisador Dr. Willard, que depois se revela o vilão, mas age sozinha em cada localidade. Mesmo quando encontra vítimas, não há envolvimento emocional ou desenvolvimento da própria personagem. $\mathrm{O}$ foco está na jogabilidade em si e na busca pelo artefato.

\section{Tomb Raider: Legend (2006)}

Aspectos estéticos: Como roupa principal do jogo, Lara Croft usa um short pequeno e uma blusa marrom curta, que vai até um pouco acima do umbigo. A blusa de manga é bastante decotada e não a deixa tão exposta somente por conta de uma pequena blusa branca por baixo. A roupa é acompanhada por elementos clássicos, como um cinto com duas pistolas, uma pequena mochila, luvas e botas pretas.

\footnotetext{
${ }^{5}$ Cutscenes ou in-game movies são sequências comuns nos jogos eletrônicos, em que o jogador possui nenhum ou pouco controle. Normalmente com gráfico mais desenvolvido que o jogo em si, interrompe a jogabilidade para avançar o enredo.
} 
Em termos de instrumentos, essa vestimenta é funcional e atende as necessidades do local e características da protagonista, além de possuir cores neutras, coincidentes com o cenário. Mas seu comprimento expõe o corpo da protagonista, sem lógica no contexto e em maior proporção se comparada com o traje clássico da série (que é utilizado em um flashback na história).

Além dessa vestimenta principal, Lara utiliza outras roupas, que variam de acordo com o cenário. Em sua mansão, a blusa branca de manga longa é justa e bastante decotada, acompanhada de uma calça preta de couro. Na ida ao Japão, a protagonista vai a uma festa e usa um vestido preto curto e bastante decotado na frente e atrás. Essa roupa se encaixa no modelo de vestimenta mais reveladora de personagens femininas e serve somente para uma presença "adequada" para a ocasião.

Para a parte no Cazaquistão e Nepal, em um cenário dominado pela neve, veste um casaco marrom com extremidades brancas e uma calça bege. Com uma blusa de lã azul de manga comprida por baixo, o traje serve ao propósito de aquecer a personagem e não expõe o corpo fora do contexto. Quando retorna a Inglaterra, Lara usa uma jaqueta preta e vermelha de couro por cima de uma blusa com um amplo decote.

O corpo de Lara Croft segue a linha original, mas de uma forma mais realista, presente em parte pelo aumento na capacidade gráfica. A cintura, apesar de ainda bem fina, é mais adequada ao de uma mulher real. O rosto é ainda marcado pelos lábios grossos, mas de forma mais suave, com o cabelo castanho agora preso em um rabo de cavalo. $\mathrm{O}$ busto bastante volumoso, característica forte na personagem e fonte de polêmica, permanece.

Relação com a temática: A capacidade da protagonista, sua determinação, sarcasmo e ocasional agressividade permanecem, mas é possível perceber uma face mais humana da personagem inglesa. A presença das tumbas, aparência e atitude da personagem remetem à forma clássica do jogo, com uma importância maior à narrativa, evidente na frequência com que cutscenes apresentam a história, interação de Lara com outros personagens e suas emoções ao longo da narrativa. A protagonista se comunica constantemente com seus auxiliares (Alister e Zip), com independência e liderança, mas também se preocupa com os companheiros, determinada a não cometer os mesmos erros do passado.

Somente na cena inicial no Japão é possível se considerar que a aparência de Lara é usada como arma ou meio para se obter algo, mas logo a protagonista entra em combate e o vestido perde completamente a sua finalidade (apesar de estar visualmente presente no resto da fase). Na grande parte do tempo, a visão dos companheiros e inimigos em relação 
à personagem é determinada pela sua capacidade, fama como "tomb raider", e atitudes ao longo da narrativa.

A história e a motivação de Lara, assim como suas reações, são definidas por uma ligação pessoal com o percurso, na ligação entre o desaparecimento de sua mãe e o artefato em questão.

\section{Tomb Raider ( 2013)}

Aspectos estéticos: Lara Croft usa uma bota marrom, blusa azulada de alças com um colar de pingente verde e uma calça bege com rasgos. Os cortes na roupa, que é remendada por faixas, são produzidos pelo combate e percurso pelo ambiente hostil da ilha ${ }^{6}$. Lara é inserida no local de maneira abrupta, permanecendo com a mesma vestimenta que usava no navio onde se encontrava antes da tempestade. Portanto, elementos clássicos, como as luvas e o suporte para armas não estão presentes ou só aparecem depois, pegos do inimigo. O visual simples e com cores neutras é desgastado e até sujo, de acordo com as condições do cenário que a protagonista enfrenta, passando grande parte do jogo coberta em lama e com ferimentos.

Entre os instrumentos do jogo, machado e arco e flecha são usados com objetivo de sobrevivência, como em escaladas, caça e combate. Para derrotar uma grande quantidade de inimigos, Lara também utiliza vários tipos de armas de fogo, todos esses itens sendo coerentes, comprovando sua capacidade no jogo.

O corpo da personagem sofreu claras transformações, mesmo quando é considerada a premissa do jogo, em que é retratada mais jovem. Parte das mudanças acontece por conta dos avanços gráficos e valorização do realismo nos jogos. $\mathrm{O}$ busto, fonte de polêmica, é aqui retratado sem uma proporção exagerada e, embora em forma, a personagem não é nem muito forte nem sexualizada. O cabelo castanho permanece preso em rabo de cavalo, mas é úmido da chuva e do suor, também com a sujeira do cenário e solto na frente. $\mathrm{O}$ rosto, apesar de bonito e de guardar semelhanças com a forma clássica, não possui feições exageradas e apelativas, fazendo uma retratação mais credível.

\footnotetext{
${ }^{6}$ A ilha Yamatai serve de cenário de sobrevivência da personagem e seus amigos nesse reboot da série, tratando de sua origem como "tomb raider".
} 
Relação com a temática: A protagonista é inserida na trama de forma vulnerável e sem experiência. O visual sombrio do jogo, com cenas violentas e bastante sangue ${ }^{7}$, é um pretexto para provocar reações mais fortes e evidenciar seu crescimento ao longo da narrativa. Há também um grande destaque para a história, especialmente para os sentimentos de Lara; o desespero, medo e frio são constantes e Lara sofre inúmeras quedas e ferimentos ao longo da narrativa, além de presenciar cenas de sacrifício e morte. É ela que necessita de salvar e ajudar os companheiros, mesmo quando isso contraria o capitão Roth ou seus amigos. A dependência que existe é emocional e diminui à medida que a protagonista ganha confiança.

A cena em que um dos inimigos se aproxima de forma a parecer uma investida sexual, não condiz exatamente com essa percepção, já que a falta de reação do jogador faz com que o indivíduo mate Lara imediatamente. A protagonista não só fere o homem, mas o mata com um tiro, para depois ficar visivelmente abalada, por ser o seu primeiro assassinato. Esse é talvez o único momento na narrativa em que a aparência da personagem é evidenciada; o medo e insegurança não indicam exatamente fraqueza no contexto apresentado, porém, se considerarmos jogos anteriores, em que é capaz e confiante desde a infância, como em Tomb Raider IV e o próprio Tomb Raider Legend aqui analisado, há certa incoerência no percurso da personagem como um todo.

Apesar de demonstrar conhecimento e inteligência, identificando artefatos e locais antigos, a própria personagem afirma que odeia tumbas e sua trajetória é determinada mais pela sua capacidade de sobreviver (a exemplo do subtítulo A Survivor is Born), do que interesse arqueológico, que dá início à trama e vai se aprofundando no decorrer da narrativa. Lara enfrenta uma grande quantidade de inimigos, geralmente ferida e sem qualquer assistência, o que comprova a sua capacidade nesse jogo. Sua personalidade se difere dos títulos anteriores, sem a ironia e confiança características, mas, ao passar por situações extremas, se torna mais fria e segura diante dos desafios, especialmente no fim da história.

7 As cenas fortes, envolvendo sangue e morte, fizeram desse jogo o primeiro da franquia a possuir uma classificação "M" (inadequado a menores de 17 anos) pela Entertainment Software Rating Board. 


\section{Efeitos nas jogadoras}

Foram selecionadas meninas que jogam regularmente (PC e/ou console) e tiveram contato com os títulos de Tomb Raider analisados na pesquisa ${ }^{8}$. Três garotas expressaram as suas opiniões a respeito da presença do público feminino e desenvolvimento de Lara Croft no decorrer da série Tomb Raider.

A respeito da possível influência do novo público feminino na indústria dos jogos, todas destacaram o aumento de jogadoras, sendo que duas afirmaram que existe uma relação entre esse público e a representação de protagonistas femininas. Porém, uma destacou que não há mudanças drásticas nesse sentido, por conta da falta de interesse de empresas: "Tirando jogos como os de RPG, que os personagens femininos são considerados opcionais, acho que ainda deve haver uma grande exploração futuramente, porém ainda é fraco".

No sentido de representação física de Lara Croft, duas preferiram a feita nos mais antigos, em especial o Legend, por representar de maneira mais graficamente evoluída, a forma clássica da série, que é vista de forma positiva: "Eu gosto do "estilo" da Lara Croft, um jeito mais mulher, mais sensual e único de ser aventureira e arqueóloga“. A aparência da protagonista nos títulos iniciais também foi indicada como natural no meio: "o modelo da personagem pra mim é consideravelmente normal, tendo em vista que na maioria dos jogos que tem personagens femininos, as mesmas possuem roupas mínimas e ficam quase nuas. Acho que é uma atração a mais ao sexo masculino, que desde a criação dos jogos, são o público alvo, apesar de tudo". A jogadora que preferiu a retratação de 2013 destaca a maior capacidade gráfica e a representação mais realista de Lara.

Todas indicaram a história e gráfico como um aspecto de progressão positiva ao longo da série. Porém, houve divergências na maneira como a personagem é inserida na trama. Uma das meninas indica que o ideal seria uma junção da representação antiga e atual, e houve oposição entre as opiniões do resto das jogadoras. Por um lado, foi evidenciada a necessidade da protagonista de aprender sozinha a lidar com as dificuldades ao longo da narrativa no jogo de 2013: "Eu gostei bem mais do novo, mostra mais a capacidade dela, deixando o jogo mais real". A outra jogadora teve preferência pela

\footnotetext{
${ }^{8}$ A escolha foi determinada a partir da presença em grupos específicos no Facebook, como Tomb Raider Brasil, Lara CroftBr e Garotas Gamers. No caso do grupo Garotas Gamers, baseou-se na curtida ou comentário de qualquer conteúdo em posts relacionados à franquia Tomb Raider.
} 
personalidade no terceiro jogo da série e revelou sua decepção a respeito da nova abordagem, destacando também o menor desafio do jogo e a inconsistência em relação à forma clássica: “o 2013 me deixou decepcionada em questão da garra da personagem comparada as anteriores, me parecia ser muito mais forte; porém, com desenvolver da história, aquele apresentou ser o primeiro contato dela com os desafios dessa geração".

\section{Conclusões da análise}

A partir dos dados obtidos, é possível concluir que houve uma diminuição da representação estereotipada da protagonista em termos gerais. $\mathrm{O}$ aspecto estético foi o que apresentou maior diminuição dessas características ao longo dos jogos, permanecendo longe de estereótipos em todos os títulos no que diz respeito a instrumentos e cores das roupas. Enquanto os dois primeiros jogos analisados apresentaram corpo com proporções exageradas, com roupas apelativas e nem sempre funcionais, na nova representação o corpo é mais realista, com traje sem exposições fora do contexto.

A respeito da presença na narrativa, houve um aumento na importância da protagonista na história. Nesse sentido específico, Legend apresenta uma coerência maior em relação às emoções: a história pessoal permite a demonstração dos sentimentos da protagonista além da frieza presente em Tomb Raider III, ao mesmo tempo a apresentando como capaz e determinada. No jogo de 2013, as emoções são mais importantes do que a aparência na relação da personagem com a história, mostrando um maior equilíbrio entre os aspectos, embora o destaque aos sentimentos também tenha revelado uma maior vulnerabilidade. Essa característica não se relaciona com a capacidade de Lara, que foi, ao longo dos três jogos analisados, igual ou superior a de outros personagens, especialmente masculinos.

Mesmo com essas conclusões, percebe-se que a reação das jogadoras, no que diz respeito à aparência da protagonista, foi preferencial para Legend. Dois motivos principais justificam esse fato: maior fidelidade à forma clássica da personagem, e visão positiva do corpo mais acentuado e roupa reveladora nesse caso. Em termos de gosto pessoal, a preferência a essa retratação foi inesperada e contrária à hipótese de reação de jogadoras. Considerando os conceitos de exploração da figura feminina, seria necessário avaliar a real preferência desse público, e quais elementos estéticos diferenciam, para esses 
consumidores, a demonstração de poder feminino e o exagero de suas características. Já a aceitação de modelos, mesmo que entendidos como negativos, é uma compreensão dos estereótipos como inerentes à própria mídia, e pode prejudicar as possíveis influências desse novo público na construção de protagonistas femininas e, portanto, na transformação dos estereótipos indesejados. Essa compreensão do meio pode também ser um dos motivos para a própria adesão a esses critérios estereotipados, quando presentes na figura feminina.

Não houve uma preferência geral ao jogo mais novo em termos de relação com a narrativa, com opiniões dispersas entre os três títulos avaliados (embora a história do novo tenha sido destacada positivamente por todas). Novamente, o resultado se relaciona com o conflito entre a forma clássica e a maior emoção e realismo na nova abordagem. Além das diferenças estéticas, alguns traços de personalidade e características de jogabilidade típicas foram também diminuídos na última versão, prejudicando, na intenção de atingir um mercado mais diverso, a aceitação do público fã da série. $\mathrm{O}$ fator unânime em relação à narrativa foi a expectativa por uma representação mais complexa, da protagonista e de personagens futuras, na relação com a temática.

Nesse sentido, os resultados indicam a possibilidade de uma interpretação ainda mais complexa e realista da protagonista, principalmente se apresentada na sua maioridade, com a independência e segurança típicas, correspondendo de forma mais adequada ao público feminino.

A evolução da narrativa e complexidade da personagem, observada em Tomb Raider, representa uma transformação que pode se intensificar não só na franquia, mas na presença de protagonistas femininas em geral. O contexto de riqueza de narrativa e realismo no meio se torna cada vez mais propício a esse fenômeno a partir da presença feminina como jogadoras, impulsionando uma representação significativa. Mesmo que a exploração da aparência ainda seja vista por algumas jogadoras e apresentada nos jogos como natural, a tendência é que as dimensões de construção psicológica e de capacidade da personagem, esperadas por esse público em crescimento, superem a sua participação como "eye candy". 


\section{Referências Bibliográficas}

ASSOCIATION, Entertainment Software. 2012 Sales, Demographic and Usage Data: Essential Facts About the Computer and Video Game Industry. <http://www.theesa.com/facts/pdfs/ESA_EF_2012.pdf>. Acessado em 01/05/2013

JANSZ, J; MARTIS, R. G. The Lara Phenomenon: Powerful Female Characters in Video Games, Netherlands. Sex Roles, 2007

KERR, Aphra. Girls/Women Just Want to Have Fun - A Study of Adult Female Players of Digital Games, 2003. In: Level Up Conference Proceedings. University of Utrecht, Utrecht, pp. 270-285.

LINKER, Report. Video Game Industry: Market Research Reports, Statistics and Analysis; Global Video Games Industry. 2013. <http://www.reportlinker.com/ci02073/Video-Game.html>. Acessado em 01/05/2013

MARTINS, Nicole et al. A Content Analysis of Female Body Imagery in Video Games, USA. Sex Roles, 2009

MIKULA, Maja. Gender and Videogames: the political valency of Lara Croft. University of Technology Sydney. Continuum: Journal of Media \& Cultural Studies, Vol. 17, No. 1, 2003

MILLER, M. K.; SUMMERS, A. Gender Differences in Video Game Characters' Roles, Appearances, and Attire as Portrayed in Video Game Magazines, USA. Sex Roles, 2007

MOU, Yi ; PENG, Wei. Gender and Racial Stereotypes in Popular Video Games. IGI Global, USA. Chapter LIII, pp 922-937, 2009 
MURRAY, J.H. Hamlet no Holodeck: o futuro da narrativa no ciberespaço. São Paulo: Itaú Cultural/ Unesp, 2003

ORRICO, Alexandre. Mercado brasileiro de games já é o quarto maior do mundo e deve continuar a crescer. Folha de S.Paulo, São Paulo, 8 out. 2012.

<http://www1.folha.uol.com.br/tec/1165034-mercado-brasileiro-de-games-ja-e-o-quartomaior-do-mundo-e-deve-continuar-a-crescer.shtml>. Acessado em 01/05/2013

PEIRCE, Charles Sanders (1931 - 1958) Collected Papers. 8 vols. Cambridge. Harvard University Press.

PIMENTA, F. J. P. (2006) Hipermídia e Ativismo Global. Rio: Sotese.

REPORTER, Hollywood. MGM Partners With GK Films for New 'Tomb Raider' Movies, 27 mar 2013. <http://www.hollywoodreporter.com/heat-vision/mgm-partners-gk-filmsnew-431375>. Acessado em 01/05/2013

SOUZA, A.; CAMURUGY, L; ALVES, L. Games e gênero: a emergência dos personagens femininos. Universidade do Estado da Bahia. VIII Brazilian Symposium on Games and Digital Entertainment, 2009.

SHELDON, Lee. Character Development and Storytelling for Games. Boston: Thomson Course Technology, 2004.

SHELDON, Lee. (2010a) Semiótica e Plataformas Interativas Multicódigos. In: Jairo Ferreira; Francisco J. P. Pimenta; Luiz Signates. (Org.). Estudos de Comunicação: transversalidades epistemológicas. São Leopoldo - RS: Unisinos, 2010, v. I, p. 187-198.

SHELDON, Lee. (2007) Semiótica, como teoria da representação, e o campo da Comunicação In COUTINHO, Iluska e Potiguara M. da Silveira Jr. Comunicação: tecnologia e identidade. Rio: Mauad X. 
TELEGRAPH, The. Lara Croft picks up six Guinness world records. Reino Unido, 21 jan. 2010. <http://www.telegraph.co.uk/technology/video-games/7037574/Lara-Croft-picks-upsix-Guinness-world-records.html>. Acessado em 01/05/2013 